\title{
Fostering Intercultural Dialogue through Literature and Creative Writing: Examples of Successful Classroom Practices
}

\author{
Matea Butković \\ Faculty of Medicine, University of Rijeka, Croatia \\ matea.butkovic@gmail.com \\ Ester Vidović \\ Faculty of Teacher Education, University of Rijeka, Croatia \\ ester.vidovic@ufri.uniri.hr
}

With the rapid changes in social diversity, higher education institutions are presented with the challenge, but also the opportunity, to encourage intercultural dialogue, which fosters the universal respect for human rights, peace, and justice. This dialogue is an on-going process and depends on the willingness of its participants not only to share their views, but also to be open to accepting diverging opinions, diversity as an enrichment to our environment, and critically analyzing even their own culture. This paper focuses on the importance of intercultural dialogue and provides a range of classroom activities (discussion topics and creative writing tasks) that have been carried out at the Faculty of Teacher Education (University of Rijeka) and the Rochester Institute of Technology (Zagreb, Croatia) and have proven useful in encouraging the students to engage in intercultural dialogue inside multicultural classrooms. While the verbal activities, such as oral practice, discussions and debates, greatly contributed to the development of the students' reading and speaking skills as well as sharing of their personal experiences, feedback on the students' creative writing, with an emphasis on the group rather than individual performance, confronted the students with some of their cultural biases (lack of racial diversity, women portrayed as victims and men as villains). The implemented activities, and the obtained findings, provide language instructors with invaluable insight into the kind of content that needs to be included in their courses in order to equip the students with the knowledge and tools to successfully navigate through multicultural environments.

Keywords: EFL, intercultural dialogue, intercultural competence, literature, creative writing

\section{Introduction}

As educators in the 21st century, we are living in a world of constant cultural motion that requires the creation of inclusive learning environments based on the principles of intercultural, democratic, and cooperative learning in 
which 'critical thinking, democratic dialogue and a holistic view are valued and encouraged throughout the whole educational process' (Cabezudo et al. 2012, 32). ${ }^{1}$ Interculturalism, ${ }^{2}$ as one of the main principles of democratic and global education, ${ }^{3}$ is oriented towards 'the analysis of oppressive social relationships, combating prejudice and discrimination and transformation of society into a state of equity' (Bartulović and Kušević 2016, 8, translated by the authors). It also highlights the importance of understanding and respecting different lifestyles and viewpoints as well as developing intercultural sensitivity' and acquiring the 'ability to cope with unclear and complex social situations and the development of skills, including verbal and non-verbal communication' (Piršl et al. 2016, 19, translated by the authors).

The major goal of intercultural ${ }^{4}$ education is the creation of a better world in which there will be no place for racism, discrimination, and domination of one person over another. In that sense, it is directed towards the whole society and to all people (Piršl et al. 2016, 50, translated by the authors). Intercultural education also seeks to 'provide the optimal environment for mutual learning by means of intercultural communication and dialogue aiming at intercultural understanding and competences' (Lasonen 2005, 400, emphasis added). Based on the research on effective intercultural communication, culturally competent individuals (a) cope effectively with the psychological

${ }^{1}$ The authors of this paper subscribe to the UNESCO recommendation of inclusive education, which is defined as 'an ongoing process aimed at offering quality education for all while respecting diversity and the different needs and abilities, characteristics and learning expectations of the students and communities, eliminating all forms of discrimination' (Inclusive Education 2008, 3).

${ }^{2}$ A multitude of terms associated with intercultural education, such as 'intercultural learning and dialogue, intercultural communication, intercultural competences, intercultural communication competence and intercultural understanding' (Lasonen 2005) reveal the complex nature of the term.

3 'The Maastricht Global Education Declaration' (Europe-Wide Global Education Congress 2002, 2) defines global education as 'education that opens people's eyes and minds to the realities of the globalized world and awakens them to bring about a world of greater justice, equity and Human Rights for all. Global education is understood to encompass Development Education, Human Rights Education, Education for Sustainability, Education for Peace and Conflict Prevention and Intercultural Education; being the global dimension of Education for Citizenship'

${ }^{4}$ Terms 'intercultural' and 'multicultural' are nowadays being used as synonyms. While 'multiculturalism' and 'multicultural education' are preferred terms in the English-speaking countries such as Australia, USA, Great Britain, Canada), 'interculturalism' and 'intercultural education' are predominately used by European authors (Sablić 2014). However, in its core, interculturalism emphasizes the mutual exchange of cultural norms and respect for all cultures, while multiculturalism refers to societies that comprise a range of ethnic groups, which live alongside one another but do not necessarily interact. 
and emotional stress of dealing with the unfamiliar, (b) quickly establish rapport with others, (c) sense other people's feelings, (d) communicate effectively with people from varying backgrounds, and (e) respond adequately to miscommunication (quoted in Giles et al. 1991). Therefore, at least two prerequisites need to be fulfilled for the students to reach the desired level of intercultural communication and deal effectively with intercultural challenges: the teaching content needs to expand beyond the borders of the traditional, often monocultural approach to education that focuses primarily on the dominant culture, and the teachers themselves need to embody the fundamental principles of intercultural competence in their everyday teaching practice.

This paper provides some examples of successful classroom practices and activities that have contributed to more open dialogue among the students in multicultural classrooms and have allowed the educators insight into content that needs to be emphasized if the goals of intercultural education are to be achieved.

\section{Fostering Intercultural Dialogue in the EFL Classroom}

Foreign language educators are provided with the opportunity, but also responsibility, to include in their curriculum the kind of topics that encourage intercultural analyses and comparisons that transcend mere factual knowledge $^{5}$ and allow students to successfully navigate through intercultural encounters. ${ }^{6}$ In doing so, educators should go beyond a linguistic code, because forms and structures of the language will not suffice to enable effective communication (Kramsch 1993; 2008, quoted in Sobkowiak 2015, 794). The path to the discovery of the complexity of intercultural education begins with intercultural dialogue.

While dialogue in the general sense of the word is crucial for 'co-habitation of subjects belonging to different cultures' (Piršl et al. 2016), the role of inter-

${ }^{5}$ Council of Europe's report 'Living Together: Combining Diversity and Freedom in 21st Century Europe' (Council of Europe 2011) goes a step further and highlights that all Member States should strive to develop intercultural competence not only as a core element of school curricula but also beyond formal education, in non-formal settings.

${ }^{6} \mathrm{An}$ intercultural encounter may be defined as 'an encounter with another person (or group of people) who is perceived to have different cultural affiliations from oneself. Such encounters may take place either face to face or virtually through, for example, social or communications media. They may involve people from different countries, people from different regional, linguistic, ethnic or religious backgrounds, or people who differ from each other because of their lifestyle, gender, social class, sexual orientation, age or generation, level of religious observance, etc.' (Huber and Reynolds 2014, 16). 
cultural dialogue is reflected in the freedom of speech, one's own choice and expression, as well as in the tolerance, equality, mutual understanding, and respect (Piršl et al. 2016, 51). Above all, intercultural dialogue is about accepting different opinions and arguments and peacefully resolving conflict. It is thereby important that the participants of intercultural dialogue do not lose the independence of their judgment during this process (Piršl et al. 2016) because the purpose of intercultural dialogue is not to 'suspend our feelings and opinions and become neutral' but rather to 'suspend our value judgements' (European Commission and the Council of Europe n. d., 6). However, establishing the kind of dialogue inside the classroom that enables all of its participants to share their views and opinions freely, and even to challenge the existing, often monocultural curriculum and co-create a more inclusive one is a major challenge for educators, but also all participants in the formal educational process.

Given the high importance attributed to intercultural dialogue at the $\mathrm{EU}^{7}$

${ }^{7}$ Several EU documents address the importance of intercultural dialogue. In the 'Declaration on Intercultural Dialogue and Conflict Prevention,' also known as the Opatija Declaration (Council of Europe 2003), intercultural dialogue is defined as 'an open and respectful exchange of views between individuals and groups belonging to different cultures that leads to a deeper understanding of the other's global perception.' The Faro Declaration (Council of Europe 2005) describes it as 'a means of promoting awareness, understanding, reconciliation, tolerance and respect for the other, of preventing conflicts and of ensuring an integrated and cohesive society' $(2005,4)$, while 'The Rainbow Paper' (Platform for Intercultural Europe 2008, 5) highlights its aim of 'turn[ing] our diversity away from socio-cultural difference into active intergroup collaboration.' In the 'White Paper on Intercultural Dialogue' (Council of Europe 2008, 10), dialogue is defined as 'an open and respectful exchange of views between individuals and groups with different background, on the basis of mutual understanding and respect' and as a key tool in 'prevent[ing] ethnic, religious, linguistic and cultural divides' on the democratic basis of shared universal values. The Council of Europe emphasizes that the objective of intercultural dialogue, as 'the oldest and most fundamental mode of democratic conversation, is to enable us 'to live together peacefully and constructively in a multicultural world and to develop a sense of community and belonging,' 'to learn to live together peacefully and constructively in a multicultural world,' and 'to develop a sense of community and belonging' (see https://www.coe.int/t/dg4/intercultural/concept_EN.asp). It also lists six crucial conditions for achieving a true, meaningful intercultural dialogue: Equal dignity of all participants; Voluntary engagement in dialogue; $\mathrm{A}$ mindset (on both sides) characterized by openness, curiosity and commitment, and the absence of a desire to 'win' the dialogue; A readiness to look at both cultural similarities and differences; A minimum degree of knowledge about the distinguishing features of one's own and the 'other' culture; The ability to find a common language for understanding and respecting cultural differences. The importance of intercultural dialogue at the EU level is also reflected in the joint decision of the European Parliament and the Council of Europe to name the year 2008 as the 'European Year of Intercultural Dialogue' with the objective to foster the role of education as important medium for teaching about diversity, increase the understanding of other cultures and developing skills and best social practices, and highlight 
level, it is imperative that it becomes an inherent component of everyday teaching practice. This, however, is no easy accomplishment. Even when teachers are aware of the importance of establishing (intercultural) dialogue and introducing intercultural topics into their subject curricula, they are faced with the challenge which approach to take as well as which topics to address. Teachers should consider how they address local and global dynamics and how the newly gained insights and knowledge might enable students to understand global changes and realities better. Such an approach also contributes to the raising of the awareness and acceptance of cultural and linguistic diversity, provided they are addressed effectively. However, this endeavor requires a collaborative approach to research topics and careful planning of the curriculum that will provide the students with multiple opportunities to learn about a core set of issues that will increase in complexity throughout their education (Gaudelli 2006) and provide them with the tools to express their opinions in a mindful and respectful manner.

Literary texts and creative writing can be a starting point for explorations of the students' views and attitudes about cultural diversity. In the context of foreign language education, the literary medium has always been linked to culture (Hoff 2017); however, in the 1990s, the focus turned away from teaching about foreign cultures to promoting the learners' intercultural competence. Emphasis was thereby placed on providing both the teacher and the students with the opportunity to engage in a holistic, human rights-based approach to education, as opposed to the traditional 'tourist approach' that gives merely a superficial glimpse into the life of different communities. Today, it is recognized that literature in the language classroom encourages not only 'dynamic learning - learning which involves the students actively and as personally ${ }^{8}$ as possible' (McRae 1991, 8) but also language development since it 'cannot occur if students are only passive recipients of the teacher's input' (Daskalovska and Dimova 2012, 1184). As Hild Elisabeth Hoff (2017) further points out, reading literature in a foreign language is in itself an intercultural experience, and since readers engage in their own and other cultures through literature, this engagement may foster intercultural learning (Kramsch 1993; Bredella 2000; Fenner 2001). Multicultural literature thereby

the central role of the media in promoting the principle of equality and mutual understanding' (European Parliament and the Council 2006).

${ }^{8}$ Personal involvement can thereby be understood as 'the readers' close contact with the characters or the engagement in the event of the story, the sharing of emotions and feelings between readers and characters, between readers and the author, and among readers themselves' (Shazu 2014, 31). 
plays a vital role in fostering intercultural given that, as Byram, Gribkova, and Starkey (2002) highlight, the intercultural dimension in teaching aims to develop learners as 'intercultural speakers or mediators who are able to engage with complexity and multiple identities and to avoid the stereotyping' (9). It is through meaningful interactions with multicultural literature that students are given the opportunity to discover 'the universality of the human experience that unites people of all backgrounds' (Stallworth, Gibbons, and Leigh 2006,478 ) and enhance their awareness of diversity (Tunnell et al. 2012).

\section{Research Aims}

The major aim of the carried-out activities was to uncover and help reduce possible discrepancies between the students' current and desired understanding of cultural diversity. In the section focusing on verbal activities, the students were encouraged to engage in discussions on race actively, in the context of the offered literary texts and everyday life, while remaining mindful of the language they use in conveying their thoughts. The aim behind the written assignments was to gain an insight into the students' explicit and implicit views on cultural diversity through creative expression.

The observations of the students' expressed opinions and the findings obtained through an analysis of their creative writing would help the educators to make appropriate changes to the educator's teaching pedagogy.

Two groups of students took part in the selected activities:

- Students enrolled in two teacher education programs (Integrated university undergraduate and graduate Study of Teacher Education and the University undergraduate study of Early and Preschool Education at the University of Rijeka), who attended the courses Children's Literature in English and Anglo-Saxon World. Countries represented included Croatia, Spain, France, Austria, Turkey, Czech Republic, Finland, and Slovenia.

- Students enrolled in two non-teacher education programs (Undergraduate studies in information technology and Undergraduate studies in International Business at the Rochester Institute of Technology in Zagreb), who attended the courses Topics in American Literature and Literature, Culture, and Media at the Rochester Institute of Technology in Zagreb. Countries represented included Croatia, Bosnia and Herzegovina, Albania, Montenegro, USA, Canada, India, Palestine, France, South Africa, Syria, Switzerland, and Russia. 
In our preparation for the activities that probed our students' views on cultural diversity, we were guided by the characteristics which Vasileiadis, Tsioumis, and Argyris (2013) highlight as crucial for educators. According to these authors, educators should: (a) consider the contents of their own perceptions on the superiority or inferiority of those who are different, (b) examine, along with their students, their experiences, cultural backgrounds, as sources of behaviors, perceptions and attitudes, through a critic of their views, as culturally determined and partial, (c) think and reflect that their views influence positively or negatively the others and (d) challenge knowledge's neutrality and to understand that knowledge is not neutral and can be subjective or objective.

During the interaction with the students, we made an effort not to lose sight of the fact that our attitudes and behaviors must reflect the principles of intercultural dialogue, that we do not use or tolerate violent communication but promptly react to offensive behavior and hate speech between the participants and that we continuously encourage the expression of different points of view and sharing of experiences. Our goal was thereby 'to accommodate the two worlds in the learner's mind [...], to sharpen the learners' awareness of similarities and differences and help them to come to terms and deal with divergent experiences' (Neuner 1997, 236).

\section{Literature and Intercultural Dialogue}

In their early stages of implementation, literary texts were mostly used 'for translation purposes and exercises on reading comprehension' (Premawardhena 2005, 92), which kept the learner's focus on the surface level of text analysis - learning new vocabulary - rather than allowing room for developing a deeper understanding of the cultural context behind the words. As Denka (2005) noted, the purpose of this approach was to turn looking up words in a dictionary into a habit. However, it has been recognized that besides linguistic benefits, literature offers humanistic and educational benefits that include empathy, tolerance, and intercultural understanding and promote critical analyses of both the native and foreign culture. Through literature, language learners become immersed 'in authentic communication and in genuine experiences which have value, importance, or significance for them' (Stern 1992, 302) and 'construct experiences of "content" in a non-trivial way which gives voice to complexities and subtleties not always present in other types of texts' (Carter and McRae 1996, xxiv).

Nowadays, literature in the foreign language classroom is used as support for the acquisition of communicative and intercultural (communicative) 
competence (Riverol 1991; Bretz 1990) since it has been recognized that it provides a 'dimension of depth' (Stevick 1976), i.e., 'the learner's mental involvement in what he or she is saying, leading to a kind of communication that is more than superficial' (Stern 1987, 48). Teaching literature in the FL classroom 'offers a new perspective in the globalized world' (Lovrović and Kolega 2019,4) given that it offers a glimpse into another culture since it is a cultural artifact. As such, its interpretation requires from the students to engage in an interplay between cultural knowledge and their personal experiences, attitudes, and values. In essence, literature provides fertile ground for a critical exploration of one's own culture and those perceived as foreign and has the potential to facilitate the kind of dialogue which can steer the learners' cultural awareness and knowledge in unexpected new directions. In other words, literature 'encourages inter- and intracultural awareness' (MaziLeskovar 2010, 10).

In the following activities, we engaged in an exploration of our students' intercultural competence by trying to uncover their explicit and implicit views on race, gender, and prejudices.

\section{Comprehension Checks and Text Analyses}

As pointed out by Henderson and May, race plays important roles in children's and adolescent literature $(2005,81)$. The author emphasizes that young readers are taught to accept the difference in a codified way, with race 'underwritten into the text with certain cultural assumptions' $(2005,81)$. When it comes to race, Henderson and May point out, the literary discourse has been marked by silence and evasion, resulting in turn in 'substitute language in which the issues are encoded, foreclosing open debate' $(2005,81)$. In that way, children encounter silences while witnessing oppressive scenes in books, thereby decoding the significance of equity from conversations of characters in the books they read.

\section{The Rabbits' Wedding by Garth Williams}

We had an opportunity to explore whether race is underwritten into a literary work with certain cultural assumptions with the fourth year students of Primary School Education at the Faculty of Teacher Education in Rijeka. The research was conducted with the students during the elective course Children's Literature in English.

The activity aimed to investigate the students' understanding of the (possible) symbolism of the rabbits' color, namely whether they represent the black and white races as had been assumed by the Southern American readership 
at the time of the book's publication. The activity comprised two parts. In the first part, the students were shown the cover of Garth Williams's picture book The Rabbits' Wedding (1986) and asked whether the colors (black and white) of the two rabbits represent human races. In the second part of the research, the students were familiarized with the crucial moments that marked the US racial discourse in the period encompassing slavery up to the 1950s. Thereupon they were asked to write down their impressions on the picture book and the author's possible intentions behind it.

The students' initial responses were compared to their written impressions. The participants' answers related to the rabbits' color only changed concerning what these colors represented at the time the book had been written and not because they had changed their minds about what the colors generally refer to (Butković and Vidović 2017, 157). Most students did not connect the color of the rabbits with the black and white colors of human races, which was in line to our initial hypothesis. The students eagerly shared their disagreement with the historical understanding of the picture book and uniformly condemned such treatment of children's literature. The conversation quickly turned to the topic of censorship, whereby the students tried to provide examples of censored authors from their home countries as well as the political reasons for their censorship.

\section{Uncle Tom's Cabin by Harriet Beecher Stowe}

Additional research has been conducted with third-year students of Primary School Education with a focus on racial nomenclature in the context of the elective course Anglo-Saxon World. First, the students studied an excerpt from Harriet Beecher Stowe's Uncle Tom's Cabin, provided from the supplement instructional material Across Cultures (Sharman 2004, 152). In the depicted scene, Simon Legree, a brutal Louisiana slave owner, buys a new slave, Tom, whom he gradually deprives of all his possessions.

The aims of the research included encouraging student-teachers to reflect on the impact of the derogatory language in the studied excerpt. We also wanted to explore their knowledge of acceptable and unacceptable racial nomenclature and its appropriateness in children's literature before discussing with them the social-political context of the period in which the novel had been written. Our aim was also to discuss the existence of racism in Croatia with the hope that the research in this area would guide us in the future framing of our curricula.

The activity was conducted during two teaching periods. In the first period, the stress was placed on text analysis, while in the second period, we carried 
out our research in the form of a questionnaire. The first activity was conducted in stages, with the first stage concentrating on the comprehension of the extract, the second on text analysis, and the third on a trans-historical analysis.

\section{Section 1}

- How is Tom dressed at the start and at the end of the scene?

- How does Legree discover Tom is a religious man?

- What changes does Legree make to Tom's clothes?

- Why does the crew of the boat find Tom's possessions so amusing?

- What possessions is Tom left with at the end of the scene?

In the first section, the students concentrated on finding the required information, which they were able to do after scanning and skimming the text. Section 2

- How would you describe Legree's treatment of Tom and his attitude towards slaves in general?

- What is symbolized by the description of how Tom is gradually deprived of all his clothes and possessions?

In the second section, the students concentrated on the symbolical meaning of the text, i.e., while Tom was being deprived of his clothes, he was also being deprived of his pride and human dignity.

Section 3. Do you think that the enslavement of black people has had a longterm effect on race relations in the USA?

The third part of the lesson gave room for a trans-historical analysis, with the students being allowed to reflect upon racial relations in the USA in the 19th century and today.

The actual research was conducted a week later in the form of a questionnaire. In the first part, the students were told to pay special attention to the words the author used when referring to black people, i.e., 'slave' and 'nigger.' In the second part of the research, the students could express their views on the possible existence of racism in Croatia/other European countries and the need to teach children about the presence of racism in society. They were also presented with 16 expressions used throughout US history when referring to American Blacks (Butković and Vidović 2019, 233). The students were encouraged to express their opinions about the appropriateness of the suggested nomenclature in children's literature and were asked to reflect upon 
the existence of racism in Croatia and the need to introduce racial topics in the first four grades of primary school.

Most students (60\%), both home and foreign, found that the term 'slave' was more neutral than the term 'nigger' and emphasized that the latter term is very negative and carries more weight (Butković and Vidović 2019, 234). They understood that the author's aim when using these words was to show the protagonist's dehumanization and deprival of his identity. The findings in the second part were somewhat surprising and disturbing because, although most students identified a great majority of offensive words, a significant percentage (25\%) did not consider terms such as 'boy' or 'auntie' offensive (Butković and Vidović 2019). The students opined that the topics related to racial issues, regardless of their delicate nature, could and should be discussed with students in junior grades of primary school. Only in this way, emphasized the students, could we educate informed and responsible citizens of the 21st century (Butković and Vidović 2019). They also expressed their concerns about the recent examples of unrest in the USA caused by biased racial politics. The discussion developed into an analysis of the racial situation in Croatia and some other countries (the home countries of the ERASMUS students).

\section{White Teeth by Zadie Smith}

The novel White Teeth also provides fertile ground for studying race in literature. The extract from the supplement instructional material Across Cultures (Sharman 2004, 159) portrays a scene in which one of the main characters, Magid Iqbal, a boy from a Bangladeshi immigrant family, changes his name to Mark Smith.

Our main aim was to develop intercultural dialogue by discussing the lives of immigrants in the UK and other European countries. Such a dialogue greatly contributes to promoting tolerance, friendship, and cooperation between people of different races, social status, habits, and traditions.

The activities were organized around three sets of questions: comprehension check, text analysis, and questions for discussion. The students first looked for information in order to answer the questions in the first section. Following are the questions.

Section 1: Comprehension

- What did Magid tell his white friends that upset his parents?

- What is his real full name?

- What work does his mother/father do? 
- Why is Magid determined to participate in the Harvest Festival?

- Why doesn't his father want him to go?

Section 2: Text Analysis

- What do items like cats, pianos, holidays in France and wooden floors symbolize for Magid?

- How is the text representative of the immigrant experience?

Section 3: Questions for Discussion

- What problems can immigrants experience in terms of clashes between their native culture and the culture of the country they live in?

- Do you think that the older and the younger generations of immigrants in your country have the same disagreements as Samad and Magid?

The three sets of questions naturally developed into a discussion linked to exploring the symbolic meaning of the things and actions that symbolically represent the way of living of immigrant families compared to domicile families. The discussion was put in a wider context, where the students freely and openly exchanged experiences about the immigrant culture in their home countries. It was interesting to hear about heterogeneous cultures such as France and Spain, and classes filled with children from numerous countries.

\section{Creative Writing and the Benefits of Teacher Feedback in Fostering Dialogue}

According to Hattie and Timperley, feedback 'is that which happens second - after a student has responded to initial instruction - when information is provided regarding some aspect(s) of the student's task performance' (2007, 82). In the carried out written assignments, the feedback provided did not seek to address the students' linguistic skills or to correct factually incorrect information; however, it nevertheless had a corrective function. The effort was made to correct some of the misconceptions about cultural diversity observed in the students' creative writing by addressing them in the follow-up discussions. No names of individual students were mentioned; the observations addressed the similarities within the group. Our approach to providing feedback relied on three elements: recognition of the desired goal, evidence about the present position, and some understanding of a way to close the gap between the two (Black and William 1998). Furthermore, the outcome 
- students' recognition of their current and shift toward the desired understanding of cultural diversity - depended not only on the educator's feedback but also on the opportunity for the students to share their opinions about the possible reasons behind their creative choices.

In the activities listed below, the educator refrained from providing the students with creative ideas or certain content that might be considered desirable in the context of the research aims. In addition to the written guidelines that were provided to each student, the only additional guideline the educator repeated when the students asked questions about the possible content of their writing was: 'Use your imagination. Feel free to include in your writing whatever you deem important for your story.'

\section{Individual Activities}

Writing the Introduction to a Murder Mystery. This activity aimed to explore inclusivity in the students' portrayal of fictional characters. It was hoped that the students would consider including in their writing ethnically diverse characters as well as characters with special needs.

Given the time restraints, the students were asked to write only the introduction to a detective story, whereby they had the full freedom in their creative expression. The students received the following instruction:

This will not be the entire story, but rather the beginning of a murder mystery. One of the key figures in the story is John Smith. Start your story with: 'It was 5 in the morning when John Smith received a phone call that would turn his day upside down.' Include the following: description of John Smith (appearance, personality, the setting, the crime (location, time, weapon, clues left behind at the crime scene), and give your story a title.

After studying the content of 164 texts, a worrying pattern was noticed. The texts revealed a disturbing lack of female characters as well as racial diversity. More precisely, there were only 11 female characters (1.68\%) out of a total of 651 characters, 10 of whom were victims of a brutal crime, and only one $(0.15 \%)$ was the protagonist. Furthermore, there was only one reference to race $(0.15 \%)$ - a homeless black man who ends up becoming the murder suspect. On the other hand, a character's whiteness was never mentioned. In essence, providing the students with the opportunity to freely express their thoughts uncovered their implicit views that men can be police officers, detectives, and even suspects, while women are reduced to the role of the vic- 
tim as well as that male characters dominate their imaginative worlds; even the female students included predominately male characters in their writing. Interestingly, the students never mentioned their characters' religious affiliations or characters with special needs. In the rare instances when sexuality was mentioned, the characters were exclusively heterosexual.

The students' feedback was almost uniform - there were no specific reasons for omitting female and/or racially diverse characters; their choices seemed to be instinctive and spontaneous rather than intentional. This rather surprising revelation became the foundation for a discussion on gender roles and the students' exposure to disabilities and ethnic diversity in their everyday lives - their immediate environment, favorite TV shows, movies, and music. However, we maintain that the aforementioned findings deserve further exploration in future research.

Writing a Chapter in a Wartime Novel. This activity aimed to explore gender roles, especially the role of women and transgender soldiers during times of war. It relied on a letter excerpt from My Confederate Girlhood: The Memoirs of Kate Virginia Cox Logan, which was abbreviated and amended with the educator's addition of an alternative ending (added after the square brackets).

The students were provided with instructions that mention a writer named A. C. Their task was to imagine themselves being the writer and to use the letter as an inspiration for a chapter in their wartime novel. This activity was carried out after the students had read Stephen Crane's Red Badge of Courage and analyzed his naturalist style of writing. To help the students with their writing, we suggested that they consider the time and setting of the plot, how a naturalist writer might describe a battle scene as well as to provide descriptions of the protagonist and other characters.

After experiencing excruciating three weeks of writer's block, A. C. comes across a letter while rummaging through a box tucked away in a dusty corner of the attic. The letter is unsigned, and the ink on the envelope no longer reveals the name of its author. As A. C. gently pulls out the crumbling paper and unfolds it, the words you are about to read below present themselves. Some parts of the letter have served their purpose and have become invisible to their reader, but others still have a role to play.

Here we made a stand, and here our company fought absolutely alone ... our men were subjected to a ranking fire. I was the first who fell. I had put on my spectacles, taken good aim, and fired my first shot. As I was in the act of re-loading, a rifle-ball struck me in the head, a little about the forehead; and the violence of the concussion felled me to 
the earth immediately. I drew off my spectacles and flung them aside. Not believing my wound a bad one, as it was not painful, I attempted to reload. But the blood was gushing over my face and blinding my eyes, and I found it impossible to do so. I knew pretty well the extent of my wound, as I had probed it with my finger as I fell. And as the gash seemed to be a deep one, I feared faintness would ensue from loss of blood. I put aside my gun for a while and put my white handkerchief inside my hat upon the wound.

By the time I had finished these precautions [...]

Another battle is upon us. I can hear them coming. I can hear their cheers.

The sound of marching feet is piercing through my ears.

The ground is shaking.

Lord, help us all. They are here.

The students' writing once again revealed a lack of character diversity. Out of 68 stories, the protagonist, who is a soldier, is male in 65 of them (95.5\%); two characters are robots $(2.9 \%)$, and the only female protagonist $(1.4 \%)$ is a nurse. There were no transgender characters. Interestingly, the characters' race, sexuality, and religious affiliations were completely omitted.

The students revealed that the inspiration behind their writing stemmed from real-life experience given that men tend to enlist in greater numbers from women, and including transgender characters was not an option they considered exploring. When reminded that this was a creative writing task and that they had the freedom to invent a new reality, they seemed perplexed. In other words, a different allocation of roles did not seem plausible to them in this context. Interestingly, in the students' fictional world of war, there is a greater chance of encountering robot soldiers than female, religious, gay, or transgender protagonists.

\section{Group Activity}

Creating the Biography of a Villain. Given that the purpose of successful intercultural communication is the achievement of dialogue that includes the exchange of thoughts and opinions, thereby acknowledging other points of view, the educator intended to provide the students with the possibility to spontaneously engage in dialogue as opposed to being directly instructed to participate in discussions. The purpose of this activity was to uncover whether there are languages or specific character traits that are perceived as menacing due to a lack of familiarity with a particular culture.

While the students were given a 15-minute time frame for the completion 
of the task, they were allowed to work for as long as they felt comfortable. Successful completion of the task depended on the students' ability to communicate ideas, accept suggestions, and jointly choose the best solutions. A total of 65 students participated in the activity, divided into 15 groups.

The examples students came up with reveal both intercultural but also intracultural differences. The vast majority of the students (13 groups) envision a villain to be middle-aged, male, with a physical disability, a very low or very high IQ and a pronounced ego. The same characteristics apply to female villains. In terms of the language, villains speak Albanian, Serbian, and Russian as well as a southern Croatian and southern American dialect. Those students who highlighted the character's dialect came from northern parts of Croatia or northern USA and Canada.

While the perception of dialects served more to lighten the mood in the classroom, it was the perception of the languages spoken in Eastern Europe and the Balkan region that revealed, as the students phrased it, a kind of 'psychological detachment' from those cultures due to geographical distances. The words uttered in those languages seemed harsh and cold to western Europeans and the North American students. The students concluded that movies and TV shows tend to portray Eastern Europeans as members of drug cartels and poverty-stricken individuals with easy morals. Given the culturally diverse classroom, it was particularly rewarding for the North American students to hear from European students about the lack of positive representations of Eastern Europeans on screen. On the other hand, Eastern European students became more aware of the lack of uplifting representations of themselves in western productions.

\section{Conclusion}

The dynamic nature of modern societies inevitably leads to a new understanding of the role of formal education, which includes the development of intercultural communicative competence from all participants in the education system. These competencies include a blend of linguistic abilities and the awareness of the value of cultural diversity; this, in turn, leads to a successful dialogue between individuals coming from different cultural backgrounds. In Croatia, the achievement of open and respectful dialogue is crucial since our classrooms are becoming meeting points of a wide range of cultural backgrounds and viewpoints with an increase of international students. Such cultural encounters enable both the students and the educators with invaluable insight into real-life global experiences that allow them to compare and contrast socio-political and cultural specificities of each coun- 
try. However, the achievement of change from the current to desired understanding of cultural diversity as well as from the reluctance to the willingness to participate in open dialogue is no easy task. It relies on the creation of a safe learning environment, a mindful choice of words, carefully chosen teaching content, as well as the educator's intercultural competence and openness to learning from the students to improve their teaching pedagogy.

The described verbal activities related to the text analyses greatly contributed to the development of the students' reading and speaking skills. Moreover, they proved as fertile ground for exploring the symbolical meaning of the text and subsequent exchanges of opinions and personal experiences. Most importantly, they served as an excellent base for developing intercultural dialogue among the students. The students got personally involved in class activities, justified their stands on racial issues, and gave interesting insights into cultural practices of their home countries. One should approach delicate topics such as race with great care, keeping in mind that they have caused turmoil throughout history. However, at the same time, we all have to be determined and promote ideas of equality, friendship, tolerance, and cooperation.

Providing feedback on the students' writing but also hearing the students' feedback on the educator's findings has proven a fruitful starting point for the improvement of intercultural competence. Being presented with an analysis, with an emphasis on the group rather than individual performance, confronted the students with some of their cultural biases while simultaneously not diminishing their creative endeavor or their value as individuals. Creating such a safe environment made the students feel more comfortable to participate in the sharing of the possible reasons behind their creative choices because they were not singled out to the group. This approach to addressing their implicit biases resulted in a joint correction or at least a greater awareness of the existence of cultural biases. Furthermore, such analyses of the students' writing provided the educators with invaluable insight into the kind of content that needs to be included in their courses that would provide both verbal and visual representations of cultural diversity.

What the preparation, execution, and follow-up phases of our activities reveal is that the educator's role in fostering respectful intercultural dialogue is key because a meaningful change requires time, effort, and reflection. However, if educators wish to close the gap between the observed present positions and the desirable ways of thinking, as well as equip the students with the knowledge and tools to navigate through multicultural environments successfully, then they need to reach outside of the traditional, often mono- 
cultural approach to education, and introduce topics and activities that challenge the students' outlooks on life and provide concrete opportunities for personal growth.

\section{References}

Bartulović, Marija, and Barbara Kušević. 2016. Što je interkulturno obrazovanje? Priručnik za nastavnike i druge znatiželjnike. Zagreb: Centar za mirovne studije.

Black, Paul, and Dylan William. October 1998. 'Inside the Black Box: Raising Standards through Classroom Assessment.' Phi Delta Kappan 80 (2): 13944.

Bredella, Lothar. 2000. 'Literary Texts and Intercultural Understanding'. In Routledge Encyclopaedia of Language Teaching and Learning, edited by Michael Byram, 382-6. London; New York: Routledge.

Bretz, Mary Lee. 1990. 'Reaction: Literature and Communicative Competence: A Springboard for the Development of Critical Thinking and Aesthetic Appreciation.' Foreign Language Annals 23 (4): 335-8.

Butković, Matea, and Ester Vidović. 2017. 'Student Primary School Teachers' Understanding of The Rabbits' Wedding Controversy.' In Razsežnosti sodobnih učnih okolij, edited by Silva Bratož, 145-60. Koper: Založba Univerze na Primorskem.

- 2019. 'Student-Teachers' Views on Racism and Racial Nomenclature in Children's Literature.' Društvene i humanističke studije DHS 2 (8): 225-48.

Byram, Michael, Bella Gribkova, and Hugh Starkey. 2002. Developing the Intercultural Dimension in Language Teaching: A Practical Introduction for Teachers. Strasbourg: Council of Europe.

Cabezudo, Alicia, Christos Christidis, Miguel Carvalho da Svilva, Valentina Demetriadou-Saltet, Franz Halbartschlager, and Georgeta-Paula Lihai. 2012. Global Education Guidelines: A Handbook for Educators to Understand and Implement Global Education. Lisbon: North-South Centre of the Council of Europe.

Carter, Ronald, and Joe McRae, eds. 1996. Language, Literature and the Learner: Creative Classroom Practice. Harlow: Longman.

Council of Europe. 2003. 'Declaration on Intercultural Dialogue and Conflict Prevention.' DGIV/CULT/PREV(2004)1E, Council of Europe, Strasbourg.

- 2005. 'Faro Declaration on the Council of Europe's Strategy for Developing Intercultural Dialogue.' DGIV/DC-FARO (2005) 8 final, Council of Europe, Strasbourg.

- 2008. White Paper on Intercultural Dialogue: 'Living Together as Equals in Dignity.' Council of Europe, Strasbourg. www.coe.int/t/dg4/intercultural /source/white\%2opaper_final_revised_en.pdf

—. 2011. 'Living Together: Combining Diversity and Freedom in 21st Cen- 
tury Europe; Report of the Group of Eminent Persons of the Council of Europe.' Council of Europe, Strasbourg. https://rm.coe.int/16806b97c5

Daskalovska, Nina, and Violeta Dimova. 2012. 'Why Should Literature Be Used in the Language Classroom?' Procedia: Social and Behavioral Sciences 46:11826.

Denka, Andrzej. 2005. Lesestrategien und Lesesteuerungsstrategien beim Einsatz literarischer Texte im Fremdsprachenunterricht. Frankfurt am Main: Lang.

Europe-Wide Global Education Congress. 2002. 'The Maastricht Global Education Declaration.' https://rm.coe.int/168070e540

European Commission and the Council of Europe. N. d. 'Guidelines for Intercultural Dialogue in Non-Formal Learning/Education Activities.' https://pjp -eu.coe.int/documents/42128013/47262115/lCD2014.pdf/73add476-4e8e $-4522-8 \mathrm{fb} 5-67 \mathrm{df} 5 \mathrm{e} 4 \mathrm{ccfc} 8$

European Parliament and the Council. 2006. 'Decision no. 1983/2006/EC of the European Parliament and of the Council of 18 December 2006 concerning the European Year of Intercultural Dialogue 2008.' Official Journal of the European Union, L 412/44-50.

Fenner, Anne-Brit. 2001. 'Dialogic Interaction with Literary Texts in the Lower Secondary Classroom.' In Cultural Awareness and Language Awareness Based on Dialogic Interaction with Texts in Foreign Language Learning, edited by Anne-Brit Fenner, 3-42. Strasbourg: Council of Europe.

Gaudelli, William. 2006. 'Convergence of Technology and Diversity: Experiences of Two Beginning Teachers in Web-Based Distance Learning for Global/Multicultural Education.' Teacher Education Quarterly 33 (1): 97-116.

Giles, Howard, Nikolas Coupland, Angie Williams, and Laura Leets. 1991. 'Integrating Theory in the Study of Minority Languages.' In The Influence of Language on Culture and Thought, edited by Robert L. Cooper and Bernard Spolsky, 113-36. New York: Mouton de Gruyter.

Hattie, John, and Helen Timperley. 2007. 'The Power of Feedback.' Review of Educational Research 77 (1): 81-112.

Henderson, Darwin L., and Jill P. May. 2005. Exploring Culturally Diverse Literature for Children and Adolescents. Boston, MA: Pearson Education.

Hoff, Hild Elisabeth. 2017. 'Fostering the "Intercultural Reader"? An Empirical Study of Socio-Cultural Approaches to EFL Literature.' Scandinavian Journal of Educational Research 63 (3): 1-22.

Huber, Josef, and Christopher Reynolds. 2014. Developing Intercultural Competence through Education. Council of Europe Pestalozzi Series 3. Strasbourg: Council of Europe.

Kramsch, Claire. 1993. Context and Culture in Language Education. Oxford: Oxford University Press.

- 2008. 'Ecological Perspectives on Foreign Language Education.' Language Teaching 41 (3): 389-408. 
Lasonen, Johanna. 2005. 'Reflections on Interculturality in Relation to Education and Work.' Higher Education Policy 18:397-407.

Mazi-Leskovar, Darja. 2010. 'Fiction for Adults Promoting Intercultural and Intracultural Understanding.' Facta Universitatis Linguistics and Literature 8 (1): 9-17.

McRae, John. 1991. Literature with a Small 'I.' Basingstoke: Macmillan.

Neuner, Gerhard. 1997. 'The Role of Sociocultural Competence in Foreign Language Teaching and Learning.' Language Teaching 29: 234-9.

Piršl, Elvi, Mirjana Benjak, Marina Diković, Matija Jelača, and Andrea Matošević. 2016. Vodič za interkulturalno učenje. Zagreb: Naklada Ljevak.

Platform for Intercultural Europe. 2008. 'The Rainbow Paper: Intercultural Dialogue; From Practice to Policy and Back.' 2008. https://ec.europa.eu/ migrant-integration/librarydoc/the-rainbow-paper---intercultural -dialogue-from-practice-to-policy-and-back-1

Premawardhena, Neelakshi Chandrasena. 2005. 'Integrating Literature into Foreign Language Teaching: A Sri Lankan Perspective.' Novitas-Royal 1 (2): 92-97.

Riverol, Jenny Elliott. 1991. 'Literature in the Teaching of English as a Foreign Language.' Revista Alicantina de Estudios Ingleses 4:65-9.

Sablić, Marija. 2014. Interkulturalizam u nastavi. Zagreb: Naklada Ljevak. Sharman, Elizabeth. 2004. Across Cultures. Harlow: Pearson Education.

Shazu, Rafiul Islam. 2014. 'Use of Literature in Language Teaching and Learning: A Critical Assessment.' Journal of Education and Practice 5 (7): 29-35.

Sobkowiak, Paweł. 2015. 'Developing Students' Intercultural Competence in Foreign Language Textbooks.' US-China Education Review 5 (12): 794-805.

Stallworth, B. Joyce, Louel Gibbons, and Leigh Fauber. March 2006. 'It's Not on the List: An Exploration of Teachers' Perspectives on Using Multicultural Literature.' Journal of Adolescent \& Adult Literacy 49 (6): 478-89.

Stern, Hans Heinrich. 1992. Issues and Options in Language Teaching. Oxford: Oxford University Press.

Stern, Susan L. 1987. 'Expanded Dimensions to Literature in ESL/EFL: An Integrated Approach.' English Teaching Forum 25 (4): 47-55.

Stevick, Earl W. 1976. Memory, Meaning, and Method. Rowley, MA: Newbury House.

Tunnell, Michael O., James S. Jacobs, Terrell A. Young, and Gregory Bryan. 2012. Children's Literature, Briefly. 5th ed. Boston, MA: Pearson Education.

Vasileiadis, Konstantinos Nikolaos, Konstantinos Alexandros Tsioumis, and Argyris Kyridis. 2013. 'The Effects of Dominant Ideology on Teachers' Perceptions and Practices towards the "Other."' International Journal of Learning \& Development 3 (1): 33-48.

Williams, Garth. 1986. The Rabbits' Wedding. New York: HarperCollins. 